\title{
Reseñas de publicaciones
}

\author{
El discurso del turismo. \\ Aspectos lingüísticos y variedades textuales \\ Liverani, Elena y Canals, Jordi (eds.), Tangram Edizioni Scientifiche, Trento, 2011. \\ ISBN: 978-88-6458-029-6
}

\section{Mariano Belenguer Jané \\ mbj@us.es}

El mundo de los viajes ha generado a lo largo de la historia de la humanidad multitud de textos extraordinariamente heterogéneos en contenidos, formas e intenciones. La semántica, la morfología y la pragmática de los relatos de viajes se combinan logrando ricas hibridaciones y diferentes discursos que se han ido modificando a lo largo de los siglos.

Hoy, en la sociedad tan compleja y mercantilizada en la que vivimos, la construcción de los universos viajeros se inserta dentro de una potente industria turística que, por lo general desvirtúa, camufla o fabrica realidades (o ficciones) bajo sutiles y estudiadas textualizaciones encaminadas, la mayoría de las veces, hacia la persuasión.

La proliferación de diferentes estructuras textuales, géneros y soportes que hoy se utilizan en torno a los viajes (es más realista decir turismo, aunque yo me resista) hace extraordinariamente oportuna la aparición de este libro coordinado por los lingüistas Elena Liverani y Jordi Canals. Los textos de viajes son en la actualidad todavía más heterogéneos y su proliferación hace que su estudio sea casi inabarcable. Guías turísticas, catálogos, reportajes de viajes, webs y blogs de viajes... se convierten en el objeto de estudio de conjunto de autores expertos reunidos en este trabajo colectivo. Utilizando el análisis del discurso como herramienta y metodología de trabajo son capaces de desentrañar el léxico, las retóricas, las estrategias y recursos que estos productos utilizan con mayor o menor eficacia.

Para comprender mejor el extraordinario trabajo realizado por los autores que han contribuido a la elaboración de este volumen, hay que insertarlo dentro de su contexto. Y este no es otro que la labor desarrollada, desde hace ya unos años, por los componentes del grupo de investigación Linguaturismo bajo el marco del Proyecto de Relevante Interés Nacional (PRIN) y que lleva por título: El Lenguaje de la comunicación turística español-italiano. Aspectos léxicos, pragmáticos e interculturales. En este proyecto participan investigadores de tres universidades: la Università degli Studi di Milano, la Università di Bologna y la Università degli Studi di Trento. Los trabajos publicados hasta la fecha por los integrantes y colaboradores de este equipo suponen un importante avance en la investigación sobre el discurso del turismo.

Volviendo a la obra concreta que nos atañe, ésta centra sus investigaciones - a través de diez capítulos - en dos ámbitos fundamentales: el análisis del léxico y las modalidades discursivas a través de los medios de edición más clásicos como el caso de las guías, reportajes de viajes o los anuncios publicitarios; y a través de los productos web, cuyos géneros y tipologías están todavía por definir. También, y no menos importante, dedica algunos capítulos a la investigación sobre la didáctica de los lenguajes y la traducción dentro del ámbito del lenguaje del turismo.

En conclusión, una obra rigurosa, novedosa e indispensable que es capaz de desentrañar, desde las estrategias más sutiles que utiliza el lenguaje publicitario, hasta aquellos recursos lingüísticos que todavía rememoran y recuerdan que un día los relatos de viajes caminaron de la mano de la literatura. Un libro que no sólo proporciona conclusiones, sino que abre el terreno y sugiere nuevas investigaciones.

Sobre la edición quiero señalar que los capítulos de este ensayo se presentan indistintamente en italiano y en castellano, según la lengua del autor. A pesar de la facilidad de lectura de la lengua italiana para el hispanohablante y viceversa, se agradecería una edición bilingüe de todos sus capítulos o una doble edición en ambas lenguas.

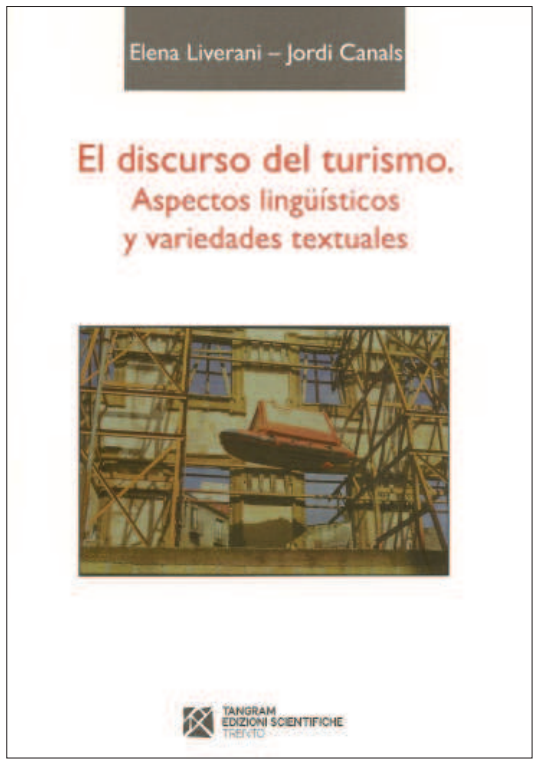

Recibido:

Reenviado:

Aceptado:

$19 / 2 / 2012$

Sometido a evaluación por pares anónimos 